\title{
Gümüşhane İlinde Yayılış Gösteren Bazı Tıbbi Bitkilerin Antioksidan ve Antimikrobiyal Aktivitelerinin ve RP-HPLC-DAD ile Fenolik Bileşenlerinin Belirlenmesi
}

\author{
Determination of Antioxidant and Antimicrobial Activities, and Phenolics Compounds by \\ RP-HPLC-DAD of Some Medicinal Plants from Gümüşhane (Turkey)
}

\author{
Kaan KALTALIOĞLU* ${ }^{\text {1,a }}$, Mustafa KARAKÖSE ${ }^{1, \mathrm{~b}}$, Hüseyin ŞAHİN ${ }^{1, \mathrm{c}}$, Ersan BEKTAŞ ${ }^{1, \mathrm{~d}}$, Kadriye \\ INAN BEKTAŞ ${ }^{2, \mathrm{e}}$ \\ ${ }^{1}$ Giresun Üniversitesi, Espiye Meslek Yüksekokulu, 28600, Giresun \\ ${ }^{2}$ Karadeniz Teknik Üniversitesi, Fen Fakültesi, Moleküler Biyoloji ve Genetik Bölümü, 61080, Trabzon
}

• Geliş tarihi / Received: 24.12.2017～• Düzeltilerek geliş tarihi / Received in revised form: 09.07.2018 • Kabul tarihi / Accepted: 04.12 .2018

\begin{abstract}
Öz
Bu çalışmada, çeşitli rahatsızlıkların tedavisinde tıbbi amaç için kullanılan ve Gümüşhane ilinden toplanan Hypericum scabrum, Laser trilobum, Turanecio hypochionaeus ve Lactuca racemosa bitkilerinin antioksidan ve antimikrobiyal özelliklerinin analizi ve fenolik bileşenlerinin belirlenmesi amaçlanmışıtır. Fenolik bileşenler diod tarama dedektörlü ters fazlı yüksek performanslı sıvı kromatografisi (RP-HPLC-DAD) analizi ile belirlenmiştir. Bitki özütlerinde belirlenen ana bileşenler, klorojenik ve kafeik asit olurken; miktarları ise sırasıyla 14.08-0.90 ve 12.76-0.35 mg fenolik/g özüt aralığında tespit edilmiştir. Antioksidan aktivite profiline bakıldığında; demir indirgeme antioksidan gücünün (FRAP) 378.04-54.10 $\mu \mathrm{M} \mathrm{FeSO}_{4} .7 \mathrm{H}_{2} \mathrm{O}$ eşdeğeri/g özüt aralığında, DPPH radikalini \%50 oranında süpürmek için gereken konsantrasyonun 483.33-45.64 $\mu \mathrm{g} / \mathrm{mL}$ aralığında, total fenolik içeriklerinin (TPC) 82.76-36.30 mg GAE/g özüt aralığında olduğu belirlenmiştir. Antimikrobiyal analiz sonuçlarında ise test edilen mikroorganizmalara karşı bitki özütlerinin düşük seviyede etki gösterdikleri belirlenmiştir. Edinilen sonuçlara göre, bu bitkiler yeni farmasötik ilaçların geliştirilmesine katkıda bulunabilirken; çeşitli hastalıkların tedavisindeki potansiyel kullanımları doz bağımlı bir şekilde klinik çalışmalarda araştırılabilir kanaati ortaya çıkmıştır.
\end{abstract}

Anahtar kelimeler: Antimikrobiyal aktivite, Antioksidan aktivite, Fenolik, Gümüşhane, Tibbi bitkiler

\begin{abstract}
This study was designed to determine antioxidant and antimicrobial properties and phenolic constitutes of Hypericum scabrum, Laser trilobum, Turanecio hypochionaeus and Lactuca racemosa which are collected in Gümüşhane (Turkey) and are used as a traditional complementary therapy for various disorders. RP-HPLC-DAD (reverse phase-high performance liquid chromatography with a diode array detector) was applied for quantitative and qualitative analysis of phenolic compounds. Chlorogenic acid and caffeic acid were found in all samples as the dominant compound ranged from 14.08 to 0.90 and 12.76 to $0.35 \mathrm{mg}$ phenolic/g extract, respectively. The antioxidant activity profile was, ferric reducing antioxidant power (FRAP) ranged from 378.04 to $54.10 \mu \mathrm{M} \mathrm{FeSO}_{4} .7 \mathrm{H}_{2} \mathrm{O} / \mathrm{g}$ extract, the concentration desired for scavenging of DPPH radicals by $50 \%$ ranged from 483.33 to $45.64 \mu \mathrm{g} / \mathrm{mL}$, while total phenolic content (TPC) ranged from 82.76 to $36.30 \mathrm{mg}$ GAE/g extract. According to antimicrobial results, plant extracts showed a weak effect against tested microorganisms. In conclusion, their potential use in treating various diseases in a dose-dependent manner might also be explored in clinical trials and obtained results might contribute to the development of new pharmaceutical drugs.
\end{abstract}

Keywords: Antimicrobial activity, Antioxidant activity, Phenolics, Gümüşhane, Medicinal plants

\footnotetext{
*a Kaan KALTALIOĞLU; kaan.kaltalioglu@gmail.com; Tel: (0454) 31014 30; orcid.org/0000-0002-4995-2657

${ }^{\mathrm{b}}$ orcid.org/0000-0003-0534-3996 ${ }^{\mathrm{c}}$ orcid.org/0000-0002-6018-1494 ${ }^{\mathrm{d}}$ orcid.org/0000-0001-9030-6908

e orcid.org/0000-0002-5909-588X
} 


\section{Giriş}

Bitkiler geçmişten günümüze pek çok hastalığın tedavisinde veya semptomlarının hafifletilmesinde kullanılan doğal kaynaklardır (Maver vd., 2015). Geleneksel tedavi yöntemlerinde folklorik bitkilerin kullanımı gelişmemiş veya gelişmekte olan ülkelerde daha çok tercih edilmekte ve pazar payı dünya genelinde giderek artmaktadır. Bu tip bitkiler yan etkilerinin nispeten daha az olduğuna inanılması, kolay ulaşılabilir olmaları gibi sebeplerle tercih edilmektedir. (Trivedi, 2006). Bitkilerin gösterdikleri tıbbi etkilerin ise içerdikleri fenolik bileşenler gibi sekonder metabolitler üzerinden gerçekleştiği düşünülmektedir. Flavonoller, izoflavanoidler, tanenler, fenolik asitler gibi fenolik bileşenler antioksidan, antimikrobiyal, antiinflamatuvar, antitümör, antidiyabet vb. aktiviteler göstererek çeşitli hastalıkların tedavi sürecinde etkin rol oynarlar (Pereira vd., 2009; Chedia vd., 2013; Mahmoudi vd., 2016; Bektas vd., 2018).

Türkiye'nin floristik zenginliği göz önüne alındığında geleneksel tıp büyük önem arz etmekte ve çok sayıda tıbbi bitki bulundurmaktadır (Faydaoğlu ve Sürücüoğlu, 2011). Hypericum (Hypericaceae) cinsi üyeleri Türkiye, İran, Almanya ve ABD gibi ülkelerde siğil, yara, egzama tedavisinde ve ayrıca ağrı kesici ve antidepresan olarak kullanılan folklorik bitkilerdir. Bu türün çiçekleri, yaprakları, toprak üstü kısımları veya bitkinin tamamı tedavi amaçlı olarak kullanılmaktadır (Greeson vd., 2001; Mazvearani vd., 2007; Korkmaz ve Karakurt, 2015). Türkiye'de yerel olarak "Karahasan çayı" olarak bilinen $H$. scabrum türü ise geleneksel olarak yara ve ülser tedavisinde, iltihap kurutma ve mide rahatsızlıklarında kullanılmaktadır (Korkmaz ve Karakurt, 2015). Eslami vd. (2011) yapmış oldukları çalışmada $H$. scabrum türünün antihipoksik ve antidepresan etki gösterdiği tespit edilmiştir. Ayrıca yapılan çalışmalarda bu cinsin üyelerinin zengin fenolik çeşitliliğe ve biyolojik aktiviteye sahip olduğu rapor edilmiştir (Jürgenliemk ve Nahrstedt, 2002; Çirak vd., 2011; Shafaghat, 2011).

Laser trilobum (Apiaceae) türü Türkiye'de genellikle "kefe kimyonu" olarak adlandirılmakta ve baharat olarak kullanılmaktadır (Doğan vd., 2014). Ayrıca yine Türkiye'de bu türün meyve kısımlarının sindirime yardımcı olmak ve karın ağrısını gidermek için geleneksel olarak kullanıldığı bildirilmiştir (Bulut vd., 2014). L. trilobum türünün antioksidan (Ebrahimzadeh vd., 2010), antimikrobiyal (Parlatan vd., 2009) ve antihemolitik (Ebrahimzadeh vd., 2010) etki gösterdiği çeşitli çalışmalarla belirlenmiştir.

Asteraceae familyasının üyeleri olan Turanecio ve Lactuca cinsleri Türkiye'de doğal olarak yetişen bitkilerdir. Turanecio yeni tanımlanan bir cins olmakla birlikte daha önceleri Senecio cinsinin altında yer almaktaydı (Hamzaoğlu vd., 2011). Türkiye florasina endemik olan ve "turanotu" olarak adlandırılan $T$. hypochionaeus türünün henüz bildirilen geleneksel bir kullanımı bulunmamaktadır. Fakat aynı cinsin başka bir üyesinin ( $T$. eriospermus) yaprak kısımlarının Türkiye'de antiinflamatuvar amaçla kullanıldığı Mükemre vd. (2015) yapmış oldukları etnobotanik çalışmada rapor edilmiştir. Lactuca cinsi ise Türkiye'de daha çok salata yapımında kullanılmakla birlikte İtalya, Hindistan ve Pakistan gibi ülkelerde yaprak kısımlarının veya bitkinin tamamının kabızlık, bronşit, astım, mide, rahatsızlıklarında kullanıldığı ve analjezik, diüretik, sedatif, hipnotik ve pürgatif özelliklere sahip olduğu belirtilmiştir (Guarino vd., 2008; Jan vd., 2009; Singh, 2012; Janbaz vd., 2013). Bu cins üyelerinin antioksidan aktiviteye sahip olduğu ve apigenin, luteolin ve kersetin gibi fenolik bileşenler içerdiği tespit edilmiştir (Terencio vd., 1992; Liu vd., 2007).

Çalışmamızda Türkiye ve çeşitli ülkelerde geleneksel olarak kullanılan ve Gümüşhane ilinden toplanan Hypericum scabrum, Laser trilobum, Turanecio hypochionaeus, Lactuca racemosa (Sin: Cicerbita racemosa) bitkilerinin DPPH, FRAP ve TPC analizleriyle antioksidan kapasitesinin, MIC yöntemiyle antimikrobiyal aktivitesinin ve RP-HPLC-DAD analizi ile fenolik bileşenlerinin saptanması ve bu bitkilerinin potansiyel kullanım alanlarına katkı sağlanması amaçlanmıştır.

\section{Materyal ve Metot}

\subsection{Bitki Örneklerinin Toplanması ve Teşhisi}

Çalışmada kullanılan tüm bitki örnekleri Gümüşhane ilinden toplanmış ve Dr. Mustafa Karaköse tarafından teşhisi gerçekleştirilmiştir. Hazırlanan herbaryum örnekleri Giresun Üniversitesi Espiye Meslek Yüksekokulu Herbaryumunda numaralandırılarak kayıt altına alınmıştır (Tablo 1).

\subsection{Bitki Özütlerinin Hazırlanması}

Çalışmada tüm bitkilerin toprak üstü kısımları kullanıldı. 
Tablo 1. Kullanılan bitki örneklerinin toplanma alanları, yerel isimleri ve herbaryum numaraları

\begin{tabular}{|c|c|c|c|}
\hline Bitki ismi & Yerel isim & Toplanma alanı & $\begin{array}{l}\text { Herbaryum } \\
\text { Numarası }\end{array}$ \\
\hline Hypericum scabrum $\mathrm{L}$. & Karahasan Çayı & Şiran/Gümüşhane, orman açıklıkları, 1700 m. & ESPH 032 \\
\hline Laser trilobum $\mathrm{L}$. & Kefe Kimyonu & $\begin{array}{l}\text { Şiran/Gümüşhane, Abies nordmanniana ve } \\
\text { Pinus sylvestris orman1, } 1890 \mathrm{~m} \text {. }\end{array}$ & ESPH 033 \\
\hline Turanecio hypochionaeus Boiss. & Turanotu & $\begin{array}{l}\text { Şiran/Gümüşhane, Abies nordmanniana } \\
\text { orman1, } 1850 \mathrm{~m} .\end{array}$ & ESPH 034 \\
\hline Lactuca racemosa Willd. & Çayır Marulu & $\begin{array}{l}\text { Şiran/Gümüşhane, Abies nordmanniana ve } \\
\text { Pinus sylvestris orman1, } 1810 \mathrm{~m} \text {. }\end{array}$ & ESPH 035 \\
\hline
\end{tabular}

Toplanan bitki örneklerinin kullanılacak kısımları ayrılarak oda sıcaklığında sabit tartıma gelinceye kadar kurutuldu. Bitki örneklerinden 5'er gramlık kartuşlar hazırlanarak $100 \mathrm{~mL}$ metanol çözücüsü içerisinde 6 saat (veya renk kalmayıncaya kadar) soxhlet aparatı ile özütleri çıkarıldı. Elde edilen özütler Whatmann filtre kağıdından geçirildi ve çözücüleri döner buharlaştırıcıda uçuruldu. Elde edilen özüt iki kısma ayrıldı. İlk kısım antioksidan ve antimikrobiyal analizlerde kullanılmak üzere saf suda, kalan kısım ise RP-HPLC-DAD analizlerinde kullanılmak üzere metanolde çözüldü. Hazırlanan özütler kullanılana kadar +4 ${ }^{\circ} \mathrm{C}$ 'de sakland.

\subsection{Fenolik Bileșen Tayini}

Fenolik bileşenler RP-HPLC-DAD analizi ile belirlendi. Bu analiz Thermo Scientific Dionex Ultimate $^{\mathrm{TM}} 3000$ (Thermo Scientific, Bremen, Germany) sistemi ile ters faz kolonu kullanılarak (Hypersil ${ }^{\mathrm{TM}}$ ODS C18 HPLC $(250 \mathrm{~mm} \times 4.6 \mathrm{~mm}$ x $5 \mu \mathrm{m})$, Thermo Scientific, USA) ikili çözücü gradient sistemi aracılığıyla gerçekleştirildi (A: $80 \%$ asetonitril-saf su; B: $2 \%$ asetik asit-saf su, başlangıç şartı $5 \% \mathrm{~B}$ ve $26 \mathrm{dk}$ içerisinde $60 \%$ B'ye varacak şekilde). Kolon sicaklığ $30{ }^{\circ} \mathrm{C}$, mobil faz akış hızı $1.2 \mathrm{~mL} / \mathrm{dk}$ ve enjeksiyon hacmi $10 \mu \mathrm{L}$ olarak analiz şartları belirlenmiştir. 12 adet standart fenolik bileșen (gallik asit, protokatekuik asit, $p$-OH benzoik asit, klorojenik asit, vanilik asit, kafeik asit, şiringik asit, $p$ kumarik asit, rutin, rosmarinik asit, benzoik asit, kersetin) $280 \mathrm{~nm}$ dalga boyunda gözlemlendi. Kromatogram alanları integrasyon ölçüm yöntemi ve mAU dedeksiyon birimi kullanarak hesaplandi.

LOD (dedeksiyon limiti) ve LOQ (ölçüm limiti) validasyon değerleri her standart için sırasıyla 3 ve 9 sinyal/gürültü $(\mathrm{S} / \mathrm{N})$ seviyesine göre hesaplandı ve alıkonma süreleri (RT) ve relatif standart sapma (RSD) değerleri ile birlikte Tablo 2 'de verildi.

Tablo 2. Kullanılan fenolik bileşenlerin standart kromatogram değerleri (RT alıkonma süresi, LOD dedeksiyon limiti, LOQ ölçüm limiti, RSD relatif standart sapma)

\begin{tabular}{|llllllll|}
\hline No & RT(dakika) & Standartlar & $\mathrm{R}^{2}$ & RSD\%(RT) & RSD\%(Alan) & LOD $\left(\mathrm{mgL}^{-1}\right)$ & LOQ $\left(\mathrm{mgL}^{-1}\right)$ \\
\hline 1 & 3.72 & Gallik Asit & 0.999 & 0.168 & 4.315 & 0.070 & 0.213 \\
2 & 6.74 & Protokatekuik Asit & 0.998 & 0.291 & 5.973 & 0.495 & 1.499 \\
3 & 10.13 & p-OH Benzoik Asit & 0.999 & 0.290 & 4.817 & 0.224 & 0.680 \\
4 & 11.46 & Klorojenik Asit & 0.997 & 0.239 & 6.177 & 0.512 & 1.550 \\
5 & 13.49 & Vanilik Asit & 0.994 & 0.168 & 6.794 & 0.171 & 0.518 \\
6 & 13.84 & Kafeik Asit & 0.999 & 0.235 & 6.861 & 0.058 & 0.175 \\
7 & 14.79 & Şiringik Asit & 0.999 & 0.082 & 5.116 & 0.096 & 0.290 \\
8 & 16.41 & p-kumarik Asit & 0.999 & 0.061 & 2.935 & 0.005 & 0.014 \\
9 & 16.63 & Rutin & 0.999 & 0.075 & 2.855 & 0.311 & 0.942 \\
10 & 18.41 & Rosmarinik Asit & 0.999 & 0.069 & 3.388 & 0.162 & 0.492 \\
11 & 18.84 & Benzoik Asit & 0.999 & 0.076 & 2.721 & 0.550 & 1.665 \\
12 & 21.71 & Kersetin & 0.999 & 0.087 & 2.268 & 0.335 & 1.014 \\
\hline
\end{tabular}




\subsection{Antioksidan Aktivitelerin Belirlenmesi}

\subsubsection{Total fenolik içerik (TPC) tayini}

Özütlerin total fenolik içerik tayini gallik asidi standart kullanarak Folin-Ciocalteu metoduna göre gerçekleştirildi (Singleton ve Rossi, 1965). İlk olarak, $680 \mu \mathrm{L}$ saf su, $20 \mu \mathrm{L}$ özüt ve $400 \mathrm{~mL}$ Folin-Ciocalteu reaktifi bir tüpte karıştırıldı ve ardından $10 \mathrm{dk}$ inkübasyona bırakıldı. Sonrasında, $400 \mu \mathrm{L} \mathrm{Na}_{2} \mathrm{CO}_{3}(10 \%)$ eklendi ve oda sicaklığında 2 saat inkübe edildi ve spektrofotometre ile 760 nm'de absorbansları okundu. Analizler üç tekrarlı olarak gerçekleştirildi. Elde edilen değerler $\mathrm{mg}$ $\mathrm{GAE} / \mathrm{g}$ özüt cinsiden verildi.

\subsubsection{Demir indirgeme antioksidan güç (FRAP) tayini}

FRAP tayini Benzie ve Strain (1996) metoduna göre gerçekleştirildi. FRAP tayini antioksidan kapasitenin belirlenmesi için kullanılan bir metot olup, $\mathrm{Fe}^{3+}$-TPTZ kompleksinin antioksidanlar varlığında indirgenerek mavi renkli kompleks $\mathrm{Fe}^{2+}$-TPTZ oluşması ve bu kompleksin 593 nm'de maksimum absorbans vermesi esasina dayanmaktadır. $3 \mathrm{~mL}$ FRAP reaktifi (TPTZ, $\mathrm{FeCl}_{3}$ ve asetat tamponu) ve $100 \mu \mathrm{L}$ özüt veya kör deney tüplerine eklenip karıştırıldı. 4 dakika sonrasında 593 nm'de absorbanslar okundu. Sonuçlar hazırlanan $\mathrm{FeSO}_{4} .7 \mathrm{H}_{2} \mathrm{O}$ kalibrasyon eğrisi ile kıyaslandı ve $\mu \mathrm{M} \mathrm{FeSO}{ }_{4} .7 \mathrm{H}_{2} \mathrm{O}$ eşdeğeri /g özüt olarak ifade edildi.

\subsubsection{2,2-difenil-1-pikrilhidrazil (DPPH) tayini}

Radikal süpürücü aktivite DPPH radikaline karşı spektrofotometrik olarak 517 nm'de ölçüldü. Kısaca özütlerden elde edilen stok çözeltilerden $50 \mu \mathrm{L}$ alınarak $5 \mathrm{~mL}$ taze olarak hazırlanmış $0.004 \%$ (w/v) DPPH çözeltisi ile karıştırıldı. Karışım $30 \mathrm{dk}$ oda sicaklığında karanlık ortamda inkübe edildi ve absorbans değerleri $517 \mathrm{~nm}$ 'de ölçüldü. Standart olarak bütillendirilmiş hidroksi tolüen (BHT) kullanıldı ve radikal temizleme aktivitesi $\% 50$ azalmaya neden olan inhibitör konsantrasyon $\left(\mathrm{IC}_{50}: \mu \mathrm{g} / \mathrm{mL}\right)$ olarak verildi. Analizler üç tekrarlı olarak gerçekleştirildi (Cuendel vd., 1997).

\subsubsection{Antimikrobiyal Aktivite Tayini}

Bitki özütlerinin antimikrobiyal aktiviteleri mikrodilüsyon metoduna göre belirlendi ve minimal inhibitör konsantrasyon (MIC) değerleri hesaplandi. Escherichia coli ATCC 25922, Bacillus subtilis subsp. spizizenii ATCC 6633,
Staphylococcus aureus ATCC 25923, Klebsiella pneumonia ATCC 700603, Pseudomonas aeruginosa ATCC 27853, Yersinia pseudotuberculosis ATCC 911, Enterococcus faecalis ATCC 29212, Bacillus cereus RSKK 709, Acinetobacter baumannii RSKK 02026, Enterobacter cloacea ATCC 13047, Candida albicans ATCC 14053 suşları Karadeniz Teknik Üniversitesi, Fen Fakültesi, Biyoloji Bölümünden temin edildi ve antimikrobiyal aktivite tayini için kullanıldı. Bitki özütlerinde son konsantrasyon 40 $\mathrm{mg} / \mathrm{mL}$ olacak şekilde saf su ile stok çözeltiler hazırland1 ve $0.45 \mu \mathrm{m}$ Millipore filtrelerden geçirilerek steril hale getirildi. 96 kuyucuk içeren plakaların her bir kuyucuğuna $100 \mu \mathrm{L}$ siv1 besiyeri (bakteriler için Mueller Hinton BrothMHB, maya için Potato Dextrose Broth-PDB) eklendi. $100 \mu \mathrm{L}$ stok özüt çözeltisi ilk kuyucuğa eklendi ve daha sonra her kuyucuğa birebir seyreltme yöntemiyle 2 kat seyreltilerek seri halinde son konsantrasyonlar1 $20-0.039 \mathrm{mg} / \mathrm{mL}$ aralığında olacak şekilde devam edildi. Son iki kuyucuk ise sterilizasyon kontrolü ve büyüme kontrolü olarak kullanıldı. Büyüme kontrolü ve tüm test kuyucuklarına $5 \mu \mathrm{L}$ bakteri süspansiyonu $\left(5 \times 10^{5} \mathrm{CFU} /\right.$ kuyucuk) inoküle edildi. Kuyucuklar $18-20$ saat boyunca uygun sicaklıklarda $(28,30$ ve $37^{\circ} \mathrm{C}$ ) inkübasyona bırakıldı. Bakteriyel büyüme $40 \mu \mathrm{L}$ INT (2-(4-iodofenil)-3-(4-nitrofenil)-5fenil-tetrazolyum-klorid) boyası eklenerek tespit edildi. Kuyucuklara INT eklenip 30 dakika inkübasyona bırakılarak mikrobiyal büyümenin olup olmadığı gözlendi ve mikrobiyal büyümenin olduğu plakalarda renk sarıdan mora dönüştü. MIC değeri büyümenin görülmediği en düșük miktarda özütü içeren konsantrasyon olarak tanımlandı. Ampisilin $(500 \mu \mathrm{g} / \mathrm{mL})$, amikasin $(500 \mu \mathrm{g} / \mathrm{mL})$ ve flukonazol $(1500 \mu \mathrm{g} / \mathrm{mL})$ standart antibakteriyel ve antifungal ajanlar olarak kullanıldı (Güllüce vd., 2003).

\section{Bulgular}

\subsection{Fenolik Bileşenler}

Hypericum scabrum, Laser trilobum, Turanecio hypochionaeus, Lactuca racemosa bitkilerinin RP-HPLC-DAD analizi ile fenolik bileșenlerinin tespitinde kullanılan 12 adet standart fenolik bileşen için kalibrasyon ve validasyon değerleri Tablo 2'de verilmiştir. Tüm bitki örneklerine ait tespit edilen fenolik bileşenler ve miktarları literatürdeki çalışmalarla kıyaslamasının daha kolay olabileceği düşünülerek mg fenolik/ g özüt ve mg fenolik/g kuru bitki cinslerinden Tablo 3'de verilmiştir. 
Protokatekuik asit, $p$-OH benzoik asit, klorojenik asit, kafeik asit ve $p$-kumarik asit tüm bitki örneklerinde tespit edilirken, rosmarinik asit sadece Hypericum scabrum özütünde, benzoik asit ise sadece Laser trilobum özütünde belirlenmiştir (Şekil 1).

Lactuca racemosa özütünde tespit edilebilen ana bileşen kafeik asit olurken, diğer tüm bitki özütlerinde ise tespit edilebilen ana bileşen klorojenik asit olmuştur. Hypericum scabrum özütünde kullanılan 12 standart bileşenin 11 tanesine ait tanımlanabilen pik tespit edilirken, bu bitki örneğini 9 tanımlanabilen pik ile Laser trilobum özütü takip etmektedir. Lactuca racemosa özütünde ise sadece 6 tane tanımlanabilen pik belirlenebilmiştir (Tablo 3).
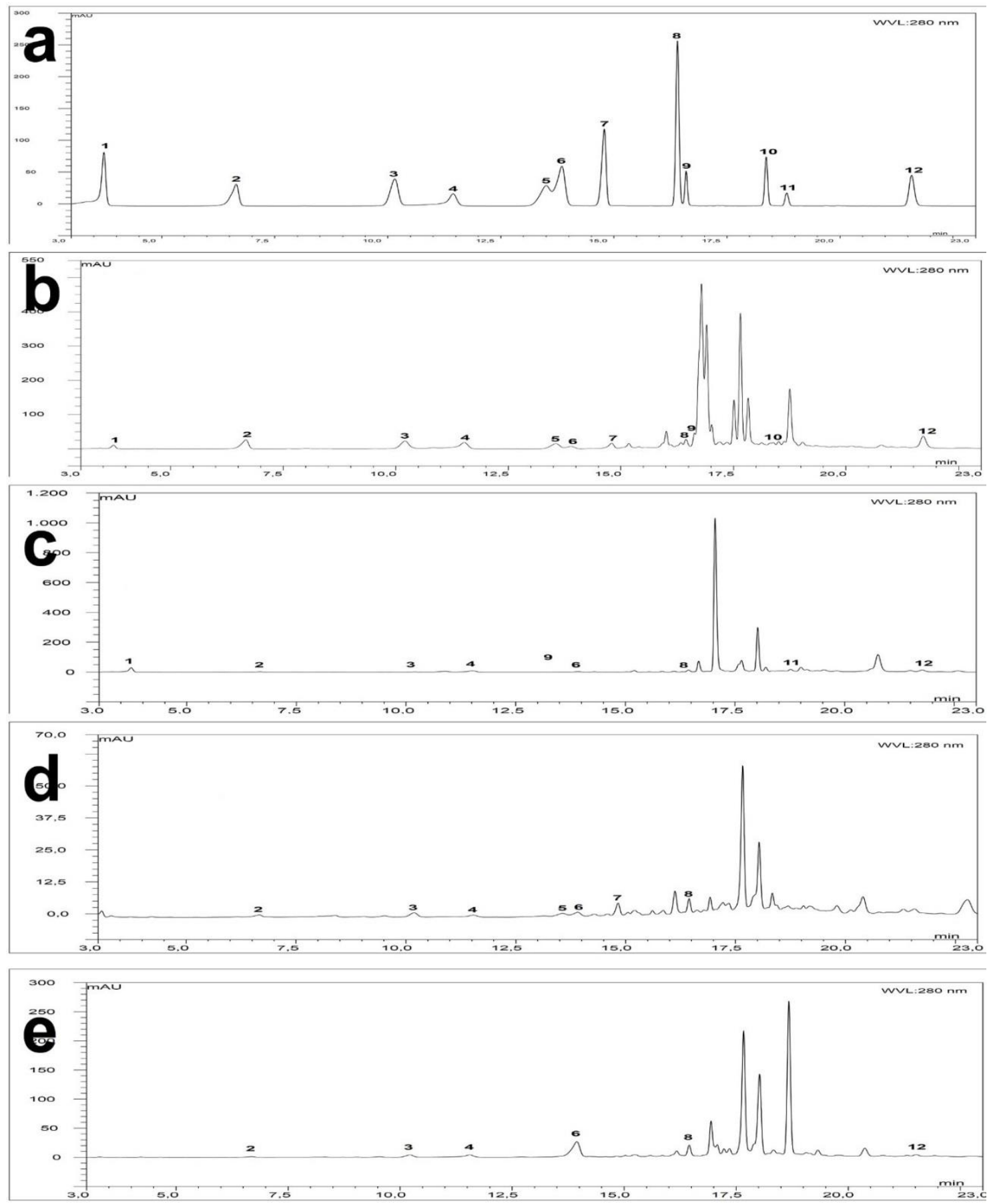

Şekil 1.Bitki özütlerinin RP-HPLC-DAD analizi ile elde edilen kromatogramları (a) standart fenolik bileşenler (b) Hypericum scabrum (c) Laser trilobum (d) Turanecio hypochionaeus (e) Lactuca racemosa (1) gallik asit (2) protokatekuik asit (3) p-OH benzoik asit (4) klorojenik asit (5) vanilik asit (6) kafeik asit (7) şiringik asit (8) $p$-kumarik asit (9) rutin (10) rosmarinik asit (11) benzoik asit (12) kersetin 
En zengin tanımlanabilen fenolik içerik Hypericum scabrum özütünde tespit edilmiştir (58.634 mg fenolik/ g özüt). Klorojenik asit (14.084 mg fenolik/ g özüt), vanilik asit (8.838 mg fenolik/ g özüt), protokatekuik asit (8.171 mg fenolik/ g özüt) ve şiringik asit (8.085 mg fenolik/ $\mathrm{g}$ özüt) sırasıyla en yüksek miktarda belirlenen fenolik bileşenlerdir.

Tablo 3. RP-HPLC-DAD ile analiz edilen bitki örneklerinin fenolik bileşenleri (t.e. tespit edilemedi)

\begin{tabular}{|c|c|c|c|c|c|c|c|c|c|}
\hline & \multirow[b]{2}{*}{ Fenolik Bileşenler } & \multicolumn{2}{|c|}{ Hypericum scabrum } & \multicolumn{2}{|c|}{$\begin{array}{c}\text { Laser } \\
\text { trilobum }\end{array}$} & \multicolumn{2}{|c|}{$\begin{array}{c}\text { Turanecio } \\
\text { hypochionaeus }\end{array}$} & \multicolumn{2}{|c|}{$\begin{array}{c}\text { Lactuca } \\
\text { racemosa }\end{array}$} \\
\hline & & $\begin{array}{l}\text { mg } \\
\text { fenolik/ } \\
\text { g özüt }\end{array}$ & $\begin{array}{l}\mathrm{mg} \\
\text { fenolik/ g } \\
\text { kuru bitki }\end{array}$ & $\begin{array}{l}\text { mg } \\
\text { fenolik/ } \\
\text { g özüt }\end{array}$ & $\begin{array}{l}\mathrm{mg} \\
\text { fenolik/ g } \\
\text { kuru bitki }\end{array}$ & $\begin{array}{l}\text { mg } \\
\text { fenolik/ } \\
\text { g özüt }\end{array}$ & $\begin{array}{l}\mathrm{mg} \\
\text { fenolik/ g } \\
\text { kuru bitki }\end{array}$ & $\begin{array}{l}\text { mg } \\
\text { fenolik/ } \\
\text { g özüit }\end{array}$ & $\begin{array}{l}\text { mg } \\
\text { fenolik/ } \\
\text { g kuru } \\
\text { bitki }\end{array}$ \\
\hline 1 & Gallik Asit & 1.462 & 0.017 & 0.260 & 0.044 & t.e. & t.e. & t.e. & t.e. \\
\hline 2 & Protokatekuik Asit & 8.171 & 0.097 & 0.380 & 0.006 & 0.346 & 0.002 & 0.404 & 0.002 \\
\hline 3 & $p$-OH Benzoik Asit & 5.710 & 0.068 & 0.298 & 0.005 & 0.593 & 0.004 & 1.876 & 0.010 \\
\hline 4 & Klorojenik Asit & 14.084 & 0.168 & 5.243 & 0.090 & 0.906 & 0.007 & 7.813 & 0.044 \\
\hline 5 & Vanilik Asit & 8.838 & 0.105 & t.e. & t.e. & 0.733 & 0.006 & t.e. & t.e. \\
\hline 6 & Kafeik Asit & 0.930 & 0.011 & 0.448 & 0.008 & 0.355 & 0.002 & 12.760 & 0.072 \\
\hline 7 & Şiringik Asit & 8.085 & 0.096 & t.e. & t.e. & 0.525 & 0.004 & t.e. & t.e. \\
\hline 8 & $p$-kumarik Asit & 0.714 & 0.008 & 0.314 & 0.005 & 0.290 & 0.002 & 1.497 & 0.008 \\
\hline 9 & Rutin & 2.266 & 0.027 & 3.843 & 0.066 & t.e. & t.e. & t.e. & t.e. \\
\hline 10 & Rosmarinik Asit & 0.298 & 0.003 & t.e. & t.e. & t.e. & t.e. & t.e. & t.e. \\
\hline 11 & Benzoik Asit & t.e. & t.e. & 4.090 & 0.070 & t.e. & t.e. & t.e. & t.e. \\
\hline 12 & Kersetin & 8.076 & 0.096 & 1.906 & 0.032 & t.e. & t.e. & 1.143 & 0.006 \\
\hline & Toplam & 58.634 & 0.696 & 16.782 & 0.326 & 3.748 & 0.027 & 25.493 & 0.142 \\
\hline
\end{tabular}

\subsection{Antioksidan Aktivite}

Bitki örneklerinin toplam fenolik içeriklerinin $36.30 \pm 0.21-82.76 \pm 0.37 \mathrm{mg}$ GAE$/ \mathrm{g}$ özüt aralığında olduğu belirlenmiştir. En yüksek içerik Hypericum scabrum özütünde, en düşük içerik ise Turanecio hypochionaeus özütünde ölçülmüştür (Tablo 4).

Hypericum scabrum, Laser trilobum, Turanecio hypochionaeus, Lactuca racemosa bitkilerinin antioksidan kapasiteleri radikal süpürme (DPPH) ve demir indirgeme güçleri (FRAP) potansiyellerinin ölçülmesi ile değerlendirilmiştir.
DPPH analizi sonucu en yüksek aktivite Hypericum scabrum özütünde $\quad\left(\mathrm{IC}_{50}\right.$ : 45.64 $\mu \mathrm{g} / \mathrm{mL}$ ), en düşük aktivite ise Turanecio hypochionaeus özütünde $\left(\mathrm{IC}_{50}: 483.33 \mu \mathrm{g} / \mathrm{mL}\right)$ belirlenmiştir. $\mathrm{IC}_{50}$ değerlerinin düşük olması yüksek antioksidan aktiviteyi göstermektedir. Demir indirgeme güçleri (FRAP) ise $\mathrm{FeSO}_{4} .7 \mathrm{H}_{2} \mathrm{O}$ eşiti/ g özüt cinsinden Tablo 4'de verilmiştir. Hypericum scabrum özütünde tespit edilen 378.04 $\pm 1.25 \mu \mathrm{M} \mathrm{FeSO}_{4} .7 \mathrm{H}_{2} \mathrm{O}$ eşdeğeri/g özüt FRAP değeri en yüksek değer olurken, Turanecio hypochionaeus özütünde belirlenen $54.10 \pm 0.84$ $\mu \mathrm{M} \mathrm{FeSO}_{4} \cdot 7 \mathrm{H}_{2} \mathrm{O}$ eşdeğeri/g özüt FRAP değeri ise en düşük değer olarak göze çarpmıştır.

Tablo 4. Bitki özütlerinin antioksidan aktivite değerleri

\begin{tabular}{|c|c|c|c|c|}
\hline & Hypericum scabrum & $\begin{array}{l}\text { Laser } \\
\text { trilobum }\end{array}$ & $\begin{array}{l}\text { Turanecio } \\
\text { hypochionaeus }\end{array}$ & $\begin{array}{l}\text { Lactuca } \\
\text { racemosa }\end{array}$ \\
\hline $\begin{array}{l}\text { TPC } \\
\text { (mg GAE/g özüt) }\end{array}$ & $82.76 \pm 0.37$ & $77.17 \pm 1.74$ & $36.30 \pm 0.21$ & $42.62 \pm 1.04$ \\
\hline $\begin{array}{l}\text { FRAP } \\
\left(\mu \mathrm{M} \mathrm{FeSO} 4 \cdot 7 \mathrm{H}_{2} \mathrm{O} \text { eşdeğeri/g özüt) }\right.\end{array}$ & $378.04 \pm 1.25$ & $306.40 \pm 2.20$ & $54.10 \pm 0.84$ & $171.02 \pm 1.34$ \\
\hline $\begin{array}{l}\mathrm{DPPH} \\
\left(\mathrm{IC}_{50}: \mu \mathrm{g} / \mathrm{mL}\right)\end{array}$ & 45.64 & 49.24 & 483.33 & 125.83 \\
\hline
\end{tabular}




\subsection{Antimikrobiyal Aktivite}

Gümüşhane ilinden toplanan bitki örneklerinin mikrodilüsyon metodu ile belirlenen antimikrobiyal aktiviteleri Tablo 5'de verilmiştir. Hypericum scabrum ve Laser trilobum özütlerinin test edilen mikroorganizmalardan $E$. coli, $B$. subtilis, S. aureus, $K$. pneumonia, $P$. aeruginosa, $Y$. pseudotuberculosis ve E. faecalis bakterilerine karşı benzer etkiler gösterdiği tespit edilmiștir. Turanecio hypochionaeus özütünde herhangi bir antimikrobiyal aktiviteye rastlanmazken, Lactuca racemosa özütünde ise sadece $E$. coli bakterisine karş1 aktivite gözlemlenmiştir. $C$. albicans mayasına karşı ise sadece Laser trilobum özütü aktivite göstermiştir. Ancak tespit edilen tüm antimikrobiyal aktivitelerin referans antibiyotiklere kıyasla oldukça zayıf olduğu görülmüştür. $P$. aeruginosa, A. baumannii ve E. cloacea bakterilerine karşı ise kullanılan bitki özütlerinden hiçbiri aktivite göstermemiştir.

Tablo 5. Bitki özütleri ve referans antibiyotiklerin minimum inhibitör konsantrasyonları (MIC değerleri $\mu \mathrm{g} / \mathrm{mL}$ özüt)

\begin{tabular}{|llllllll|}
\hline & $\begin{array}{l}\text { Hypericum } \\
\text { scabrum }\end{array}$ & $\begin{array}{l}\text { Laser } \\
\text { trilobum }\end{array}$ & $\begin{array}{l}\text { Turanecio } \\
\text { hypochionaeus }\end{array}$ & $\begin{array}{l}\text { Lactuca } \\
\text { racemosa }\end{array}$ & Ampis-ilin & Amika-sin & Flukonazol \\
\hline E. coli & 4000 & 4000 & - & 4000 & 7.8 & 0.49 & - \\
B. subtilis & 4000 & 4000 & - & - & 0.98 & 0.49 & - \\
S. aureus & 2000 & 4000 & - & - & 0.49 & 0.98 & - \\
K. pneumonia & 2000 & 4000 & - & - & - & 0.49 & - \\
P. aeruginosa & - & - & - & - & - & 0.49 & - \\
Y. pseudotuberculosis & 250 & 250 & - & - & 125 & 31.2 & - \\
E. faecalis & 2000 & 2000 & - & - & 1.9 & 62.5 & - \\
B. cereus & 4000 & - & - & - & - & 0.49 & - \\
A. baumannii & - & - & - & - & 7.8 & 0.98 & - \\
E. cloacea & - & - & - & - & - & 0.98 & - \\
C. albicans & - & 4000 & - & - & - & - & 1.46 \\
\hline
\end{tabular}

\section{Tartışma ve Sonuç}

Günümüzde gıda, kozmetik, sağlık gibi pek çok alanda çeşitli amaçlarla kullanılan bitkiler genellikle göstermiş oldukları biyolojik aktiviteler ve içerdikleri sekonder metabolitler açısından değerlendirilirler (Bektas vd., 2018). Çalışmamızda ise Türkiye ve çeşitli ülkelerde geleneksel olarak kullanılan ve Gümüşhane ilinden toplanan Hypericum scabrum, Laser trilobum, Turanecio hypochionaeus ve Lactuca racemosa bitkilerinin bazı biyolojik aktiviteleri ve RP-HPLC-DAD analizi ile fenolik bileșenleri saptanmıştır.

Fenolik bileşenler, genel olarak fenolik asitler ve flavonoidler olmak üzere 2 grup altında değerlendirilmektedirler. Çalışmamızda ilk gruba giren gallik asit, protokatekuik asit, $p$-OH benzoik asit, klorojenik asit, vanilik asit, kafeik asit, şiringik asit, $p$-kumarik asit, rosmarinik asit, benzoik asit ve flavonoidler grubuna giren rutin ve kersetin standartları bitki özütlerinde araştırılmıştır. Bulgularımız neticesinde protokatekuik asit, $p$-OH benzoik asit, klorojenik asit, kafeik asit ve $p$-kumarik asidin tüm bitki örneklerinde var olduğu tespit edilmiștir (Tablo 3). Hidroksinnamik asit esterlerinden biri olan klorojenik asit Hypericum scabrum, Laser trilobum ve Turanecio hypochionaeus bitkilerinin ana bileşeni olarak belirlenirken, bir diğeri olan kafeik asit ise Lactuca racemosa bitkisinde tespit edilmiştir. Klorojenik asit insan diyetinde en bol bulunan polifenollerden biri olmakla birlikte çeşitli çalışmalarda antioksidan ve antibakteriyel etki gösterdiği bildirilmiştir (Kang ve Lee, 2014). Ayrıca deneysel inflamatuvar hastalıklarda koruyucu etki gösterdiği (Yun vd., 2012; Lee vd., 2013), farklı mide ülseri modellerinde mide koruyucu etki gösterdiği (Shimoyama vd., 2013) ve gastroözofajial reflü hastalığını hafiflettiği (Kang ve Lee, 2014) çeşitli in vivo çalışmalarda rapor edilmiştir. Çalışmamızda kullandığımız bitki örneklerinin daha önceden belirtildiği üzere mide, sindirim ve inflamatuvar rahatsızlıklarda folklorik olarak kullanıldığı göz önüne alındığında, klorojenik asidin bu bitkilerin gösterdiği tıbbi etkilerde önemli bir rolü olduğu düşünülebilir. Ek olarak, tüm bitki örneklerinde tespit edilen kafeik asidin kolit hastalığında antiinflamatuvar etki gösterdiği (Ye vd., 2007), protokatekuik asidin ise yapilan in vivo bir çalışmada umut vaat eden derecede antiinflamatuvar ve analjezik aktivite gösterdiği belirtilmiştir (Lende vd., 2011).

Çalışmamızda Hypericum scabrum özütünde benzoik asit hariç kullanılan tüm standart fenolik 
bileşenler tespit edilmiştir (Şekil 1). Hypericum scabrum bitkisinin içerdiği klorojenik asit, rutin ve kersetin (Chen vd., 2013; Gopalakrishnan vd., 2016) fenolikleri nedeniyle yara, ülser vb. vakaların tedavisinde etkili olabileceği düşünülebilir. Çeşitli çalışmalarda ise klorojenik asit, rutin ve kersetin fenoliklerinin yara iyileşmesi sürecini geliştirebileceği rapor edilmiştir (Almeida vd., 2012; Chen vd., 2013; Gopalakrishnan vd., 2016). Ayan vd. (2009) yapmış oldukları çalışmada Hypericum scabrum bitkisinden elde edilen yaprak ve çiçek özütlerinde bizim sonuçlarımızı destekler nitelikte olup klorojenik asit, rutin ve kersetin bulunduğunu bildirmiştir. Laser trilobum özütünde ana bileşenler olarak klorojenik asit (5.24 mg/g özüt), benzoik asit (4.09 mg/g özüt) ve rutin $\quad(3.84 \quad \mathrm{mg} / \mathrm{g}$ özüt) belirlenmiştir. Ebrahimzadeh vd. (2010) L. trilobum bitkisi ile yapmış oldukları araştırmada bitkinin içeriğinde gallik asit, rutin ve kersetin bulunduğunu bildirmiştir. Ancak çalışma sadece bu üç fenolik bileşene ait standartlar kullanılarak gerçekleştirilen kantitatif bir çalışma olduğu için oldukça sınırlıdır. Çalışmamızda Turanecio hypochionaeus özütünde dedeksiyon limiti dâhilinde tespit edilebilen fenolik içerik diğer bitki özütlerine kıyasla daha düşük bulunmuştur ( $3.75 \mathrm{mg} / \mathrm{g}$ özüt). Klorojenik asit $(0.9 \mathrm{mg} / \mathrm{g}$ özüt), vanilik asit $(0.73$ $\mathrm{mg} / \mathrm{g}$ özüt) ve $p$-OH benzoik asit ( $0.59 \mathrm{mg} / \mathrm{g}$ özüt) ana bileşenler olarak belirlenmiştir. Albayrak vd. (2017) yapmış oldukları çalışmada Turanecio cinsinde genel olarak baskın bileşenlerin klorojenik asit, kafeik asit ve $p$-kumarik asit olduğunu bildirilmiştir. Lactuca racemosa özütünde kafeik asit (12.76 mg/g özüt), klorojenik asit $(7.81 \mathrm{mg} / \mathrm{g}$ özüt) ve $p$-OH benzoik asit $(1.87$ $\mathrm{mg} / \mathrm{g}$ özüt) fenolikleri dominant bileşenler olarak çalışmamızda belirlenmiştir. Literatüre bakıldığında Lactuca racemosa bitkisinin fenolik bileşenleri üzerine bir çalışma bulunmadığından dolayı elde edilen bulgular ancak aynı cinsin diğer türleri ile kıyaslanabilir. Terencio vd. (1992) yapmış oldukları ince tabaka kromatografisi ve HPLC-DAD analizleri neticesinde Lactuca viminea bitkisinin apigenin, luteolin ve kersetin içerdiğini rapor etmiştir.

Bilindiği gibi birçok bitki antioksidan aktivite göstermektedir. Bitkilerin bu özellikleri içerdikleri fenoliklerin radikal süpürme, elektron transferi ve metal iyonu şelasyonu yeteneklerinden kaynaklanmaktadır (Pereira vd., 2009). Oksidatif dengenin bozulması sonucu ortaya çıkan oksidatif stresin gastrointestinal rahatsızlıklar da dahil olmak üzere çok sayıda hastalığın patogenezinde rol oynadığ düşünülmektedir. Antioksidanlar ise oluşan oksidatif stresin zayıflatılmasında önemli rol oynamaktadır (Bhattacharyya vd., 2014). DPPH radikali süpürme tayininin hassas, kolay ve ekonomik bir yöntem olduğu düşünülmektedir (Kedare ve Singh, 2011). Çalışmamızda süpürücü aktiviteyi temsil eden $\mathrm{IC}_{50}$ değerleri 45.64-483.33 $\mu \mathrm{g} / \mathrm{mL}$ aralığında tespit edilmiştir. Düşük $\mathrm{IC}_{50}$ değeri yüksek antioksidan aktiviteye belirtmektedir. Total fenolik içerik tayini antioksidan kapasitenin hızlı bir şekilde gözlemlenebilmesi için kullanılan bir yöntemdir. Analizlerimiz sonucunda özütlerin toplam fenolik içeriklerinin 36.30-82.76 mg GAE/g özüt aralığında olduğu belirlenmiştir. FRAP tayini ise bitki örneklerinin bir antioksidan aktivite belirteci olan indirgeme yeteneklerini değerlendirmek için yapılmıştır. Tespit edilen FRAP değerlerinin 54.10 ile 378.04 $\mu \mathrm{M} \quad \mathrm{FeSO}_{4} \cdot 7 \mathrm{H}_{2} \mathrm{O}$ eşdeğeri/g özüt aralığında olduğu görülmüştür. Sonuçlara bakıldığında DPPH, FRAP ve total fenolik içerik değerleri arasında iyi bir korelasyon olduğu görülmektedir. Çalışmamızda Hypericum scabrum özütünün gerçekleştirilen tüm antioksidan aktivite analizlerinde en yüksek değere sahip olduğu gözlemlenmiştir (Tablo 4). En düşük aktivite ise Turanecio hypochionaeus özütünde belirlenmiştir. Shafaghat (2011) Hypericum scabrum bitkisinin çiçek, yaprak, gövde ve tohum kısımlarının önemli derecede DPPH süpürücü etkiye sahip olduğunu bildirmiştir. Sonuçlarımıza benzer şekilde Laser trilobum bitkisinin antioksidan aktiviteye sahip olduğu Ebrahimzadeh vd. (2010) tarafından tespit edilmiş ve TPC değeri $75 \pm 3 \mathrm{mg}$ GAE/g özüt olarak bildirilmiştir. Bir başka çalışmada ise Gan ve Azrina (2016) DPPH, FRAP ve TPC tayinleri aracillğıyla, Malezya'dan toplanan farklı Lactuca sativa (bir başka Lactuca türü) varyetelerinin antioksidan özelliklere sahip olduğunu bildirmiş̧ir. Ayrıca, Albayrak vd. (2017) yapmış oldukları biyolojik aktivite çalışmasında çeşitli Turanecio türlerinin antioksidan aktiviteye sahip olduğu tespit edilmiştir. Elde edilen sonuçlar değerlendirildiğinde test ettiğimiz tüm özütlerin antioksidan aktivite gösterdiği belirlenmiş olup, Hypericum scabrum ve Laser trilobum özütlerinin test edilen diğer bitki özütlerine kıyasla daha yüksek aktiviteye sahip olduğu söylenebilir. Özellikle bu iki tür oksidatif stres kaynaklı çeşitli rahatsızlıkların (cilt, sinir, mide gibi) tedavisinde yardımcı olarak kullanılabilir.

Hypericum scabrum, Laser trilobum, Turanecio hypochionaeus ve Lactuca racemosa bitkilerinden elde edilen özütler 11 farklı mikroorganizmaya karşı antimikrobiyal açından test edilmiştir. Mikrodilüsyon yöntemi sonucunda elde edilen MIC değerlerine baktığımızda test edilen 
mikroorganizmalara karşı en yüksek aktivitelerin Hypericum scabrum ve Laser trilobum özütlerinde olduğu belirlenirken Turanecio hypochionaeus özütünden herhangi bir antimikrobiyal aktivite gözlemlenmemiştir (Tablo 5). Ancak tüm belirlenen aktivitelerin referans antibiyotiklere kıyasla oldukça zayıf olduğu görülmüştür. Sonuçlarımızı destekler nitelikte Hypericum scabrum bitkisinin hekzan özütünün Staphylococcus aureus, Bacillus subtilis, Enterococcus faecalis ve Escherichia coli bakterilerine karşı farkl1 derecelerde antimikrobiyal aktivite gösterdiği Shafaghat (2011) tarafından rapor edilmiştir. Ayrıca, Parlatan vd. (2009) yapmış oldukları çalışmada Laser trilobum meyve özütünün Staphylococcus aureus, Proteus vulgaris, Proteus mirabilis, Bacillus cereus, Enterococcus faecalis, Klebsiella pneumonia ve Escherichia coli bakterilerine karş1 antimikrobiyal etki gösterdiğini rapor etmiştir.

$\mathrm{Bu}$ bilgiler 1şı̆̆ında Hypericum scabrum ve Laser trilobum bitkilerinin çalışmamızdaki diğer bitkilere kıyasla daha yüksek antioksidan ve antimikrobiyal aktiviteye sahip olduğu söylenebilir. Özellikle incelenen bu iki türün, içerdikleri fenolik bileşenler, antioksidan ve antimikrobiyal özellikleri göz önüne alındığında çeşitli rahatsızlıkların tedavisinde faydalı olacağ 1 düşünülebilir. Elde edilen sonuçlar bu bitkilerin potansiyel kullanım alanlarının genişletilmesine katkı sağlayacaktır.

\section{Kaynaklar}

Albayrak, S., Aksoy, A., Yaşar, A., Yurtseven, L. ve Budak, Ü., 2017. Phytochemical ve Biological Activities of five Turanecio Hamzaoglu (Asteraceae) Species from Turkey. Current Enzyme Inhibition, 13, 49-55.

Almeida, J. S., Benvegnu, D.M., Boufleur, N., Reckziegel, P., Barcelos, R.C., Coradini, K., de Carvalho, L.M., Bürger, M.E. ve Beck, R.C., 2012. Hydrogels containing rutin intended for cutaneous administration: efficacy in wound healing in rats. Drug Development and Industrial Pharmacy, 38, 792-799.

Ayan, A.K., Radušienė, J., Çirak, C., Ivanauskas, L. ve Janulis, V., 2009. Secondary metabolites of Hypericum scabrum ve Hypericum bupleuroides. Pharmaceutical Biology, 47, 847-853.

Bektas, E., Kaltalioglu, K., Sahin, H., Turkmen, Z. ve Kandemir, A., 2018. Analysis of phenolic compounds, antioxidant and antimicrobial properties of some endemic medicinal plants. International Journal of Secondary Metabolite, $5,75-86$.
Benzie, I.F. ve Strain, J.J., 1996. The ferric reducing ability of plasma (FRAP) as a measure of "antioxidant power": the FRAP assay. Analytical Biochemistry, 239, 70-76.

Bhattacharyya, A., Chattopadhyay, R., Mitra, S. ve Crowe, S.E., 2014. Oxidative stress: an essential factor in the pathogenesis of gastrointestinal mucosal diseases. Physiological Reviews, 94, 329-354.

Bulut, G., Tuzlacı, E., Doğan, A. ve Şenkardeş, İ., 2014. An ethnopharmacological review on the Turkish Apiaceae species. Journal of Faculty Pharmacy of Istanbul University, 44, 163-179.

Chedia, A., Ghazghazi, H., Brahim, H. ve Abderrazak, M., 2013. Secondary Metabolite, antioxidant ve Antibacterial Activities of Teucrium polium L Methanolic Extract. International Journal of Agronomy ve Plant Production, 4, 1790-1797.

Chen, W.C., Liou, S.S., Tzeng, T.F., Lee, S.L. ve Liu, I.M., 2013. Effect of Topical Application of Chlorogenic Acid on Excision Wound Healing in Rats. Planta Medica, 79, 616-621.

Cuendel, M., Hostettmann, K. ve Potterat, O., 1997. Iridoid glucosides with free radical scavenging properties from Fagraea blumei. Helvetica Chimica Acta, 80, 1144-1152.

Çirak, C., Radušienė, J., Janulis, V., Ivanauskas, L., Çamaş, N. ve Ayan, A.K., 2011. Phenolic constituents of Hypericum triquetrifolium Turra (Guttiferae) growing in Turkey: variation among populations ve plant parts. Turkish Journal of Biology, 35, 449-456.

Doğan, A., Bulut, G., Tuzlacı, E. ve Şenkardeş, İ., 2014. A review of edible plants on the Turkish Apiaceae species. Journal of Faculty Pharmacy of Istanbul University, 44, 251-262.

Ebrahimzadeh, M.A., Nabavi, S.M., Nabavi, S.F., Eslami, B. ve Rahmani, Z., 2010. Antioxidant ve antihaemolytic activities of the leaves of Kefe cumin (Laser trilobum L) Umbelliferae. Tropical Journal of Pharmaceutical Research, 9, 441-449.

Eslami, B., Nabavi, S.F., Nabav, S.M., Ebrahimzadeh, M.A. ve Mahmoudi, M., 2011. Pharmacological activities of Hypericum scabrum L. European Review for Medical ve Pharmacological Sciences, 15, 532-537.

Faydaoğlu, E. ve Sürücüoğlu, M.S., 2011. Geçmişten Günümüze Tıbbi ve Aromatik Bitkilerin Kullanılması ve Ekonomik Önemi. Kastamonu Üniversitesi Orman Fakültesi Dergisi, 11, 5267. 
Gan, Y.Z. ve Azrina, A., 2016. Antioxidant properties of selected varieties of lettuce (Lactuca sativa L.) commercially available in Malaysia. International Food Research Journal, 23, 23572362 .

Gopalakrishnan, A., Ram, M., Kumawat, S., Tvean, S. ve Kumar, D., 2016. Quercetin accelerated cutaneous wound healing in rats by increasing levels of VEGF ve TGF- $\beta 1$. Indian Journal of Experimental Biolology, 54, 187-195.

Greeson, J. M., Sanford, B. ve Monti, D. A., 2001. St. John's wort (Hypericum perforatum): a review of the current pharmacological, toxicological, ve clinical literature. Psychopharmacology (Berl), 153, 402-414.

Guarino, C., De Simone, L. ve Santoro, S., 2008. Ethnobotanical study of the Sannio area, Campania, Southern Italy. Ethnobotany Research ve Applications, 6, 255-317.

Güllüce, M., Sökmen, M., Daferera, D., Ağar, G., Özkan, H., Kartal, N., Polissiou, M., Sökmen, A. ve Şahin, F., 2003. In vitro antibacterial, antifungal, ve antioxidant activities of the essential oil ve methanol extracts of herbal parts ve callus cultures of Satureja hortensis L. Journal of Agricultural ve Food Chemistry, 51, 3958-3965.

Hamzaoğlu, E., Budak, Ü. ve Aksoy, A., 2011. A new genus, Turanecio, of the Asteraceae (tribe Senecioneae ). Turkish Journal of Botany, 35, 479-508.

Jan, G., Khan, M. ve Jan, F., 2009. Medicinal Value of the Asteraceae of Dir Kohistan Valley, NWFP, Pakistan. Ethnobotanical Leaflets, 13, 12051215.

Janbaz, K.H., Latif, M.F., Saqib, F., Imran, I., Zia-UlHaq, M. ve De Feo, V., 2013. Pharmacological Effects of Lactuca serriola L. in Experimental Model of Gastrointestinal, Respiratory and Vascular Ailments. Evidence-Based Complementary and Alternative Medicine, 2013, 1-9.

Jürgenliemk, G. ve Nahrstedt, A., 2002. Phenolic Compounds from Hypericum perforatum. Planta Medica, 68, 88-91.

Kang, J.W. ve Lee, S.M., 2014. Protective effects of chlorogenic acid against experimental reflux esophagitis in rats. Biomolecules ve Therapeutics, 22, 420-425.

Kedare, S.B. ve Singh, R.P., 2011. Genesis and development of DPPH method of antioxidant assay. Journal of Food Science and Technology, $48,412-422$.
Korkmaz, M. ve Karakurt, E., 2015. An ethnobotanical investigation to determine plants used as folk medicine in Kelkit (Gümüşhane/Turkey) district. Biological Diversity ve Conservation, 8, 290-303.

Lee, C.H., Yoon, S.J. ve Lee, S.M., 2013. Chlorogenic acid attenuates high mobility group box 1 (HMGB1) ve enhances host defense mechanisms in murine sepsis. Molecular Medicine, 18, 1437-1448.

Lende, A.B., Kshirsagar, A.D., Deshpvee, A.D., Muley, M.M., Patil, R.R., Bafna, P.A. ve Naik, S.R., 2011. Anti-inflammatory and analgesic activity of protocatechuic acid in rats ve mice. Inflammopharmacology, 19, 255-263.

Liu, X., Ardo, S., Bunning, M., Parry, J., Zhou, K., Stushnoff, C., Stoniker, F., Yu, L. ve Kendall, P., 2007. Total phenolic content ve DPPH radical scavenging activity of lettuce (Lactuca sativa L.) grown in Colorado. LWT - Food Science ve Technology, 40, 552-557.

Mahmoudi, S., Khali, M., Benkhaled, A., Benamirouche, K. ve Baiti, I., 2016. Phenolic ve flavonoid contents, antioxidant ve antimicrobial activities of leaf extracts from ten Algerian Ficus carica L. varieties. Asian Pacific Journal of Tropical Biomedicine, 6, 239-245.

Maver, T., Maver, U., Stana Kleinschek, K., Smrke, D.M., ve Kreft, S., 2015. A review of herbal medicines in wound healing. International Journal of Dermatology, 54, 740-751.

Mazvearani, M., Yassaghi, S., Rezaei, M., Mansourian, A. ve Ghaemi, E., 2007. Ethnobotany ve Antibacterial Activities of Two Endemic Species of Hypericum in North-East of Iran. Asian Journal of Plant Sciences, 6, 354-358.

Mükemre, M., Behçet, L. ve Çakılcıoğlu, U., 2015. Ethnobotanical study on medicinal plants in villages of Çatak (Van-Turkey). Journal of Ethnopharmacology, 166, 361-374.

Parlatan, A., Sariçoban, C. ve Özcan, M.M., 2009. Chemical composition ve antimicrobial activity of the extracts of Kefe cumin (Laser trilobum L.) fruits from different regions. International Journal of Food Sciences ve Nutrition, 60, 606617.

Pereira, D.M., Valentão, P., Pereira, J.A. ve Verade, P.B., 2009. Phenolics: From Chemistry to Biology. Molecules, 14, 2202-2211.

Shafaghat, A., 2011. Antioxidant, antimicrobial activities ve fatty acid components of flower, leaf, stem and seed of Hypericum scabrum. Natural Product Communications, 6,1739-1742. 
Shimoyama, A.T., Santin, J.R., Machado, I.D., de Oliveira e Silva, A.M., de Melo, I.L., ManciniFilho, J. and Farsky, S.H, 2013. Antiulcerogenic activity of chlorogenic acid in different models of gastric ulcer. Naunyn-Schmiedeberg's Archives of Pharmacolog, 386, 5-14.

Singh, K.N., 2012. Traditional knowledge on ethnobotanical uses of plant biodiversity: a detailed study from the Indian western Himalaya. Biodiversity Research ve Conservation, 28, 63-77.

Singleton, V.L. ve Rossi, J.A., 1965. Colorimetry of total phenolics with phosphomolybdicphosphotungstic acid reagents. American Journal of Enology and Viticulture, 16,144-158.

Terencio, M.C., Sanz, M.J., Fonseca, M.L., Manez, S. ve Ríos, J.L., 1992. Phenolic Compounds from
Lactuca viminea L. Zeitschrift fur Naturforschung C, 47, 17-20.

Trivedi, P., 2006. Medicinal Plants: New Delhi, Traditional Knowledge, IK International, 258p.

Ye, Z., Henderson, A., Liu, Z., Lee, K., Lee, S.O. ve Wannemuehler, M.J., 2007. Anti-inflammatory effect of caffeic acid, rutin ve hypoxoside in $\mathrm{C}_{3} \mathrm{H}$ mouse model of colitis. Faseb Journal, 21, A361.

Yun, N., Kang, J.W. ve Lee, S.M., 2012. Protective effects of chlorogenic acid against ischemia/reperfusion injury in rat liver: molecular evidence of its antioxidant ve antiinflammatory properties. Journal of Nutritional Biochemistry, 23, 1249-1255. 